\title{
Potash, An Essential for Plant Growth
}

The Wide Scattering and Low Concentration of America's Deposits, and What We Can Do About It

Bv George H. Dacy

$\Upsilon_{\text {deposits in the world oc- }}^{\text {HF }}$ cur in the United States and are made much of whereas our potash holdings, which are more than twenty times as large, are little used because they are spread over such an extensive area and because the deposits are of low concentration, none of them averaging much over 10 per cent. Most of the combinations in which potash occurs in the natural state are neither soluble in water nor in acid-circumstances which render their profitable salvage for commercial uses almost impossible. The chief source of all potash salts is a class of igneous rocks known as the feldspar group. Weathering and exposure leach the potash from these safety deposit vaults and lay it down in the soil, in the ocean or in inland depressions. Subsequently, when the water into which this potash has been carried evaporates, soluble deposits are formed. The potash liberated from disintegrated rock is taken up and stored in plants and may be recovered by burning the plant. Hence there are three natural sources of potash: rocks, salty lakes or soluble deposits and plant materials.

Every plant needs potash if it is to make healthy and vigorous growth and profitable crop yields are possible only where the green, growing plants have access to plenty of this food. Potash starvation is evidenced when the leaves of the plant become brown and unhealthy looking and the stems become weak and brittle. Plenty of potash enables a plant better to resist the attacks of fungous diseases, it produces fleshy fruits of fine flavor and texture and it provides sustenance essential to normal growth and development. A problem which has long been of particular concern to the national Department of Agriculture has been the matter of making the most of our natural potash supplies. The government experts have investigated and experi-

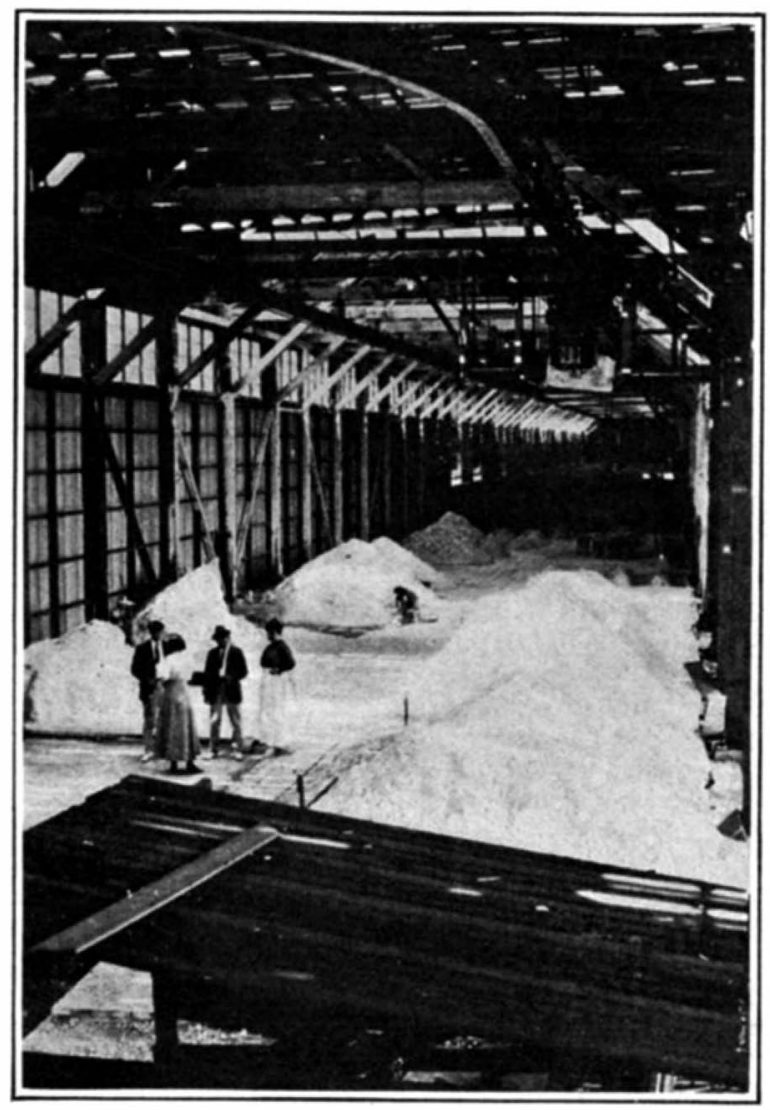

Potash salts obtained from the brine of Searles Lake, Cal.

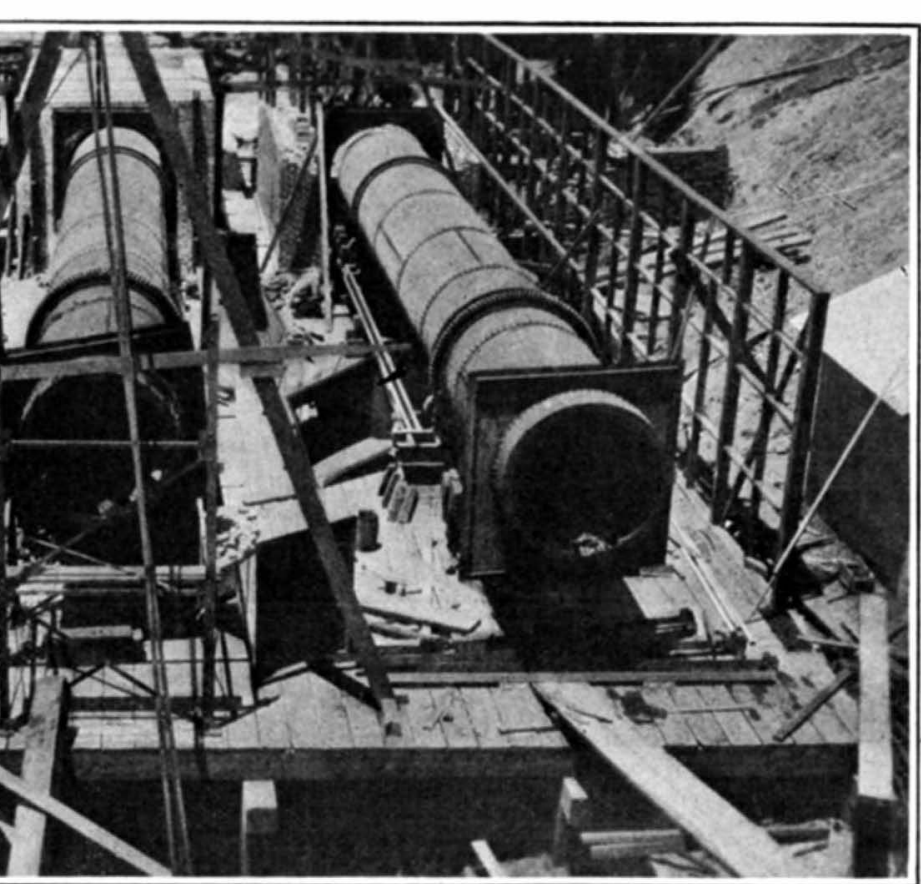

Dryers in a California plant where potash is extracted from kelp

with an average loss of about 87,000 tons of potash which was carried away in the fumes previous to the inception of an efficient method of conserving these waste gases. The largest amount of potash recovered in this way since the perfection of this salvage system has been 1621 tons, which that year was 5 per cent of the total supply produced in this country. The trouble has been that the potash volatilized from some plants was too small in amount to save, while in other instances so much dust was collected with the potash that it did not pay to leach the material nor to ship it for direct use as fertilizer. It is anticipated that shortly either a mechanical method of separating the potash and dust during collection will be devised or a system of reducing the amount of dust which can

mented with this and that method of reclamation and salvage and have built the foundation for what potentially promises to develop into a national industry which to a certain extent, if properly handled, may be able to compete with the imported potash from France and Germany.

Attempts have been made to use the mineral rocks rich in potash directly as fertilizers, but the result have not been favorable, the expenses of application being out of ratio with the benefits obtained from such practices. The practical plan perfected has featured the treatment of the material with acids or in other ways to render the potash soluble before using it for fertilizing purposes. The fact that most of the minerals and rocks are very low in potash content has complicated this problem as, although. successful methods of extracting and rendering soluble the potash were devised, the value of the fertilizer freed did not justify the expenses of these operations. Up to this time, unfortunately, no mine-run rock has been dis covered in the United States which contains as high percentage of potash as the deposits of Germany and France in which the potash is already soluble. Th most satisfactory results have obtained from recovering potash as a by-product from some of the industries where potash-rich rocks are used as raw materials.

The Federal Bureau of Soils reports, "A study was made of potash recovery from rocks which showed that the most practical results occurred where silicate rock was ignited with lime as in the manufacture of cement or by the direstion of the rock with lime and water under pressure. In the first process potash is volatilized and passes from the kilns in the process of burning, being collected on electrical precipitators, while in the second it passes into solution during the digestion. In both cases the residue is suited for the manufacture of cement or other building material. A the present time both of these methods evolved by the government soil chemists are being developed on a commercial scale."

"The process of digesting the potash silicates with lime and steam under pressure has occupied our attention and research activities for some time," said $\mathrm{Mr}$. W. H. Ross of the Bureau of Soils when the writer interviewed him recently, "and it has been found possible with pressure such as can readily be maintained in the industries to accomplish a very high percentage extraction of potash. This process is now being developed on an elaborate scale for the treatment of greensands-certain soils occurring along the Atlantic Coast from Delaware and New Jersey on south to the Carolinas, which are rich in potash-with the object of producing bricks and other building material in addition to potash. As a market is found for such building materials, this doubtless will prove a profitable but limited source of potash."

The domestic cement plants in this country produce approximately $86,000,000$ barrels of cement annually, escape from the cement plants will be perfected.

Potash can also be recovered from blast furnaces as it is volatilized as an impurity from ore, coke and limestone used in the charges. The Bureau of Soils is now investigating such sources of potash recovery and has already ascertained that the percentage of potash in the dust that escapes from some blast furnaces is much higher than that contained in the richest cement dust. However, the practice at most blast furnaces is to purify the gases by the use of a.wet purification system which causes the potash fumes to be lost so far as commercial recovery is concerned. The federal authorities are now striving to perfect dry purification method which will permit of the saving of this potash as they have demonstrated that such a system would feature the conservation of potash at a low cost

The world's largest potash deposits in Germany and Alsace were formed by the shutting off of an arm of the

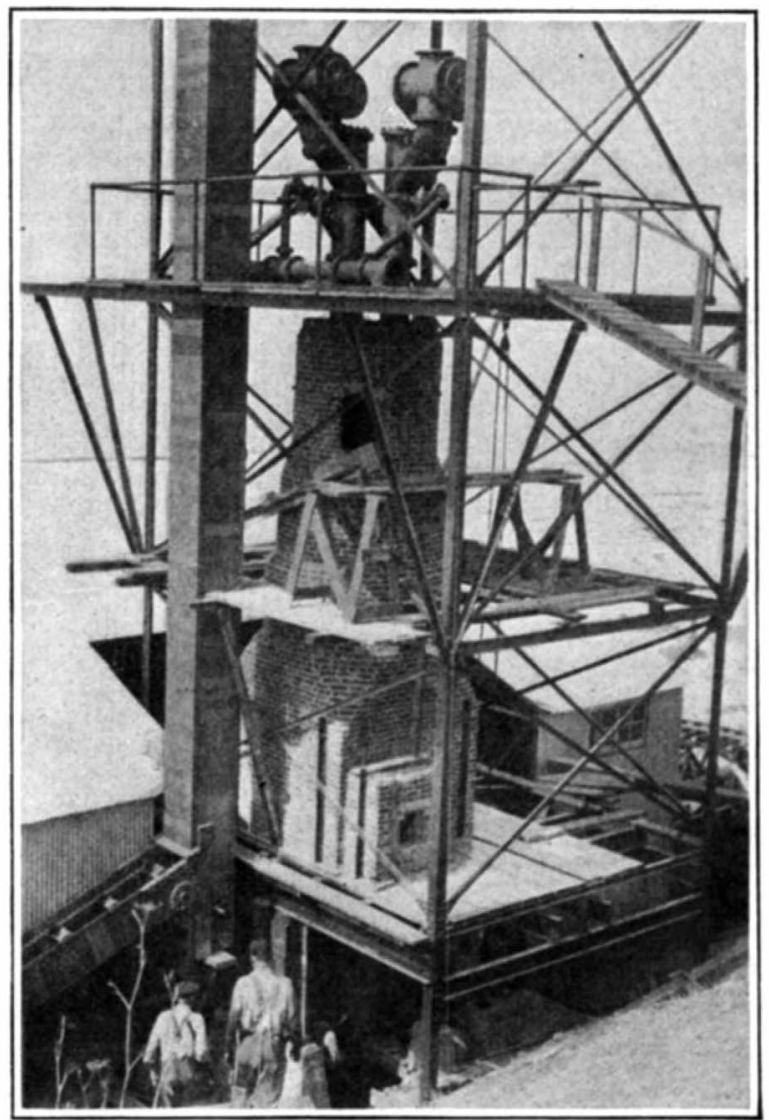

Retort furnace used in getting the potash out of the sea-weed 


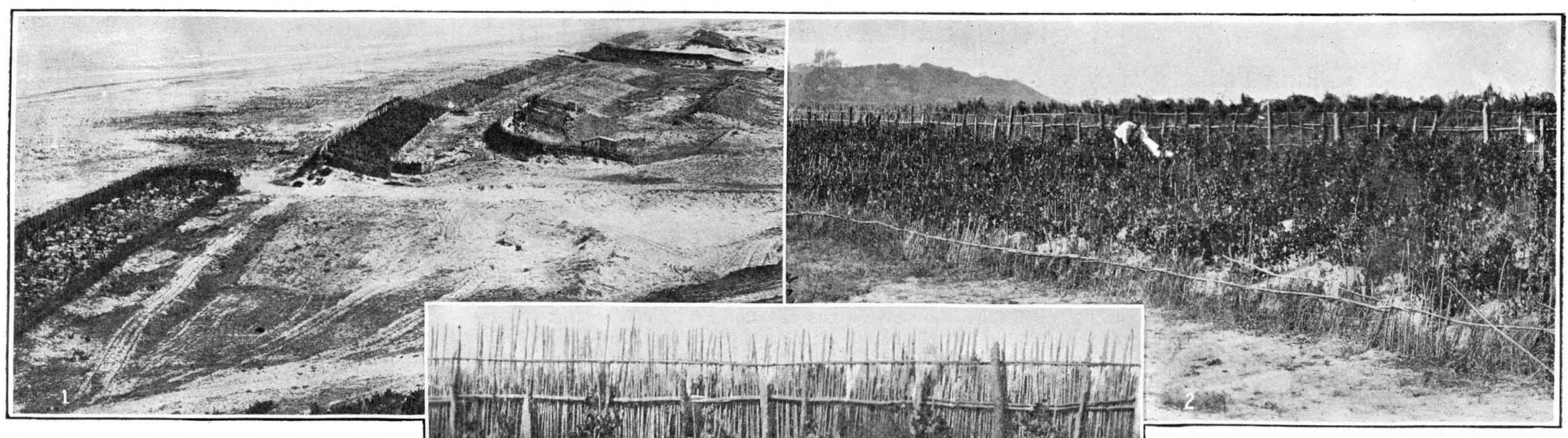

sea by a peculiar bar of land which acted like a trap permitting the sea water to flow into the bay at high tide, but, subsequently, not allowing these waters to recede as the tide ebbed. As these waters evaporated, soluble deposits of potash and othèr salts were built up; and, finally, when the bay was permanently landlocked, a large area of salts in some places 5000 feet deep had been stored away. Small deposits in western $\mathrm{Ne}$ braska, California and Utah have resulted in this country from the evaporation of fresh lake water.

"The lakes from which these deposits have been formed have not been evaporated completely, but have simply been reduced to a potash-bearing brine which in some instances contains as much as 25 per cent of potash," remarked Mr. Ross during our conversation. "This potash is recovered by pumping the brine from the lakes, concentrating it in special evaporators and finally drying the chemical in rotary kilns. During a recent five-year period, the recovery of potash from these lakes represented 43 per cent of our total domestic production, and the future of the industry will depend principally on government experiments now under way to improve these methods of extraction. It is hoped that solar radiation may be harnessed for concentrating the brine; this would markedly reduce the expenses. This is possible as the concentration of the brine as it occurs in the lakes is greatest during the dry season."

"The deposit at Searles Lake, California," continued Mr. Ross, "is the largest natural storage of soluble pot ash salts in the United States. The salts in the brine of this lake contain considerable amounts of soluble borax which is injurious to crops. Hence it is necessary to eliminate this material from the potash by the crystallization of the recovered salt. This method has been perfected to the extent that the potash as pre pared for use in fertilizers contains less than 0.5 per cent of borax, an amount which is not injurious to plant growth."

Sugar beets, wood, wool, kelp and tobacco are all rich in potash, but none of these materials except kelp is treated primarily for the recovery of potash, although their wastes are utilized in this manner. Frequently, these wastes are distributed over such a large territory that it is impractical to attempt to recover the potash. For example, the total amount of potash in the ash of wood burned as waste and that used for fuel amounts to more than 140.000 tons annually - which is about 56 per cent of the amount of potash which we customarily import during normal times. The great majority of this potash emanating from wood ashes is lost so far as economic use for fertilizer purposes is concerned.

A heavy expense is involved in evaporating the large volume of water from kelp and sugar residues. The total potash in the average annual sugar-beet crop amounts to approximately 20,000 tons. During manufacture, this potash remains in solution and a certain part of it is found in the final molasses, a goodly portion of which is fed to live stock and ultimately recovered for fertilizer in the re

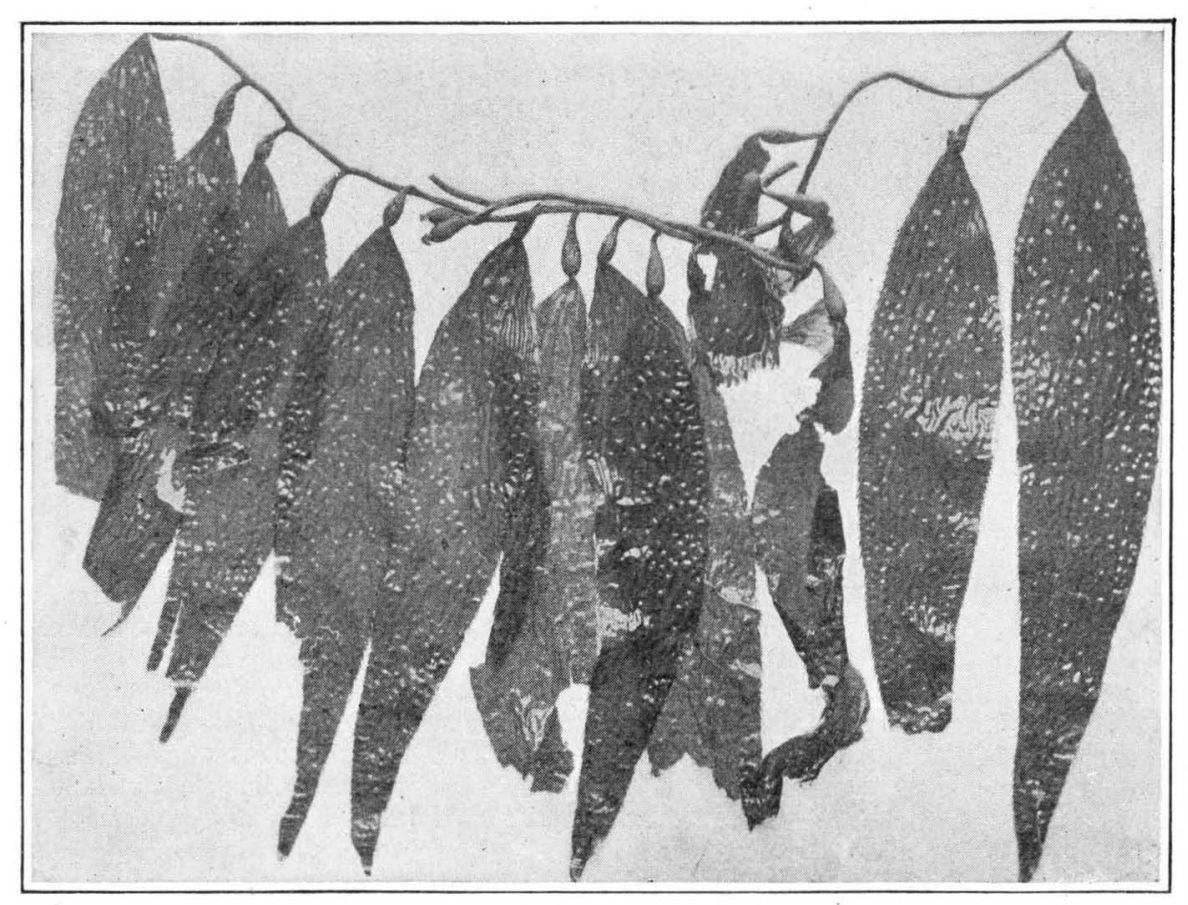

Giant kelp of the Pacific coast, one of the organic sources of potash

city of potash; the commercial treatment is tco costly to be practical under normal conditions. At present, the Bureau of Soils is experimenting to determine a practical method of saving potash from kelp which can be practiced during normal times. Uncle Sam reports that by subjecting dried kelp to destructive distillation, there can be volatilized such products as ammonia, oils, creosote and pitch in such a manner that potash salts, active carbon and iodine may be recovered from the residue. The results show that these other products will yield sufficient revenue to enable the recovered potash salts to be marketed successfully in competition with potash of foreign origin.

\section{A Seaside Vineyard}

THE grape finds, in latitudes widely 1 scattered, the conditions necessary for its development. It is only necessary that it receive in abundant profusion the light and the vivifying heat of the sun. Nevertheless, it is something of a shock to find vineyards along the Atlantic coast of France, down at the foothills of the Pyrenees and within a mile or two of the sea. Vineyards, to be sure, are found at various points along the dunes of the Mediterranean shore, but their situation is ordinarily such as to protect them against

sultant manure. A second portion is used in alcohol production, the still residues being concentrated and used as potash ferti'izers. The remaining portion, about one-half of the to al, is subjected to a special precipitation process ihich abstracts the residue sugar remaining in the molasses. Potash occurs in the wast water incm this process and is recovered by evaporation. However, unless these waste waters are found to yield other valuable products besides potash, it is doubtful if ever much more than 4000 tons of potash a year will be salvaged in this manner. The extraction of potash from kelp was rendered 